\title{
Binding of Curcumin to Senile Plaques and Cerebral Amyloid Angiopathy in the Aged Brain of Various Animals and to Neurofibrillary Tangles in Alzheimer's Brain
}

\author{
Mayu MUTSUGA ${ }^{1)}$, James Kenn CHAMBERS ${ }^{1)}$, Kazuyuki UCHIDA'), Meina TEI ${ }^{1)}$, Takao MAKIBUCHI ${ }^{2}$, \\ Tatsuya MIZOROGI ${ }^{3)}$, Akihiko TAKASHIMA ${ }^{3)}$ and Hiroyuki NAKAYAMA ${ }^{1) *}$ \\ ${ }^{1)}$ Department of Veterinary Pathology, Graduate School of Agricultural and Life Sciences, The University of Tokyo, 1-1-1 Yayoi, \\ Bunkyo-ku, Tokyo 113-8657, Japan \\ ${ }^{2}$ National Saigata Hospital, Joetsu-shi, Niigata 949-3193, Japan \\ ${ }^{3)}$ RIKEN, Brain Science Institute, 2-1 Hirosawa, Wako-shi, Saitama 351-0198, Japan
}

(Received 29 June 2011/Accepted 19 August 2011/Published online in J-STAGE 2 September 2011)

ABSTRACT. The binding of curcumin to senile plaques (SPs) and cerebral amyloid angiopathy (CAA) was examined in the aged brain of various animal species and a human patient with Alzheimer's disease (AD), together with its binding to neurofibrillary tangles (NFTs). Brain sections were immunostained with anti-amyloid $\beta$ protein 1-42 (A $\beta 42)$ and anti-amyloid $\beta$ protein $1-40$ (A $\beta 40)$ antibodies. These sections were also stained with alkaline Congo red, periodic acid-methenamine silver (PAM), and curcumin $(0.009 \%$ curcumin solution) with or without formic acid pretreatment. The sections from the AD brain were also immunostained for anti-paired helical filament-tau (PHF-tau), and were stained with Gallyas silver for NFTs. Some SPs in the AD, monkey, dog, bear, and amyloid precursor protein transgenic mouse (APP Tg-mouse) brains contained congophilic materials, and were intensely positive for curcumin. In addition, curcumin labeled some diffuse SPs negative for Congo red in the AD, monkey, bear, and APP Tg-mouse brains. In all animals, CAA was intensely positive for both Congo red and curcumin. The specific curcumin staining activity was lost by formic acid pretreatment. In the AD brain, NFTs positive for PHF-tau and Gallyas silver were moderately stained with curcumin. These findings indicate that curcumin specifically binds to the aggregated $\mathrm{A} \beta$ molecules in various animals, and further to phosphorylated tau protein, probably according to its conformational nature.

KEY WORDS: $\beta$ amyloid, cerebral amyloid angiopathy, curcumin, neurofibrillary tangle, senile plaque.

doi: 10.1292/jvms.11-0307; J. Vet. Med. Sci. 74(1): 51-57, 2012

Senile plaques (SPs), cerebral amyloid angiopathy (CAA), and neurofibrillary tangles (NFTs) are the most characteristic histopathological features in the brains of patients with Alzheimer's disease (AD). SPs and CAA consist of amyloid $\beta$ protein $(\mathrm{A} \beta)$, and they are detected by Congo red or periodic acid-methenamine silver (PAM) staining. SPs are morphologically classified into two types: diffuse plaques (DPs) and mature plaques (MPs). DPs are the earliest stage of plaque formation, and negative for Congo red [29]. MPs are the progressive stage of $\mathrm{A} \beta$ aggregation and positive for Congo red [28]. MPs also have swollen neurites or glial hallow. On the other hand, NFTs are formed in the cytoplasm of a neuron as aggregates of highly phosphorylated tau, a microtubule-associated protein. NFTs are detected clearly by Gallyas silver staining. These histopathological features are frequently observed in the aged brains of various nonhuman animal species. SPs and CAA have been observed in the brain of aged nonhuman primates [7, 17, 21, 24], dogs [3, 9, 16, 24, 26], cats [18], a camel [19], bears [6, 27], a wolverine [22], and a great spotted woodpecker [20], whereas NFTs have been reported

\footnotetext{
* Correspondence to: Nakayama, H., Department of Veterinary Pathology, Graduate School of Agricultural and Life Sciences, The University of Tokyo, 1-1-1 Yayoi, Bunkyo-ku, Tokyo 1138657, Japan.

e-mail: anakaya@mail.ecc.u-tokyo.ac.jp
}

(C)2012 The Japanese Society of Veterinary Science only in a chimpanzee [23], sheep [5], bears [6], and a wolverine [22].

Curcumin, a yellow phenolic pigment and an ingredient for curry, has potent protective and curative activities against neoplastic-, inflammatory-, amyloid and oxidantassociated disorders $[1,8,13]$. It has been reported that curcumin binds to $A \beta$ aggregates in vivo and inhibits the formation of SPs $[2,10,11,30]$. Because of its specific binding ability, use of curcumin has been expected to prevent or treat AD. Recent investigations have demonstrated that SPs, CAA, and NFTs are detected by curcumin staining in AD model mice (APPswe/PS1dE9 mice) [10] as well as AD brains [14]. However, such binding of curcumin is not well known in animals other than mouse and human.

In the present study, we examined the binding of curcumin to SPs and CAA in the aged brain of various animal species, and to NFTs in the AD brain.

\section{MATERIALS AND METHODS}

Tissue samples and histology: We examined the cerebral cortex from an AD patient, a Japanese macaque, dogs, a cat, an American black bear, a Bactrian camel, a great spotted woodpecker, and an amyloid precursor protein transgenic mouse (APP Tg-mouse) (APP23, The Jackson Laboratory, Bar Harbor, ME, U.S.A.). Sex, age, and breed of the animals are shown in Table 1. Brain tissue samples were fixed 
Table 1. Histopathologic features of the brain of the aged animals examined

\begin{tabular}{|c|c|c|c|c|c|c|c|c|}
\hline \multirow{2}{*}{$\begin{array}{l}\text { Case } \\
\text { No. }\end{array}$} & \multirow[t]{2}{*}{ Species } & \multirow{2}{*}{$\begin{array}{l}\text { Breed or } \\
\text { remark }\end{array}$} & \multirow[t]{2}{*}{ Sex } & \multirow[t]{2}{*}{ Age } & \multicolumn{2}{|c|}{ SPs } & \multirow[t]{2}{*}{ CAA } & \multirow[t]{2}{*}{ NFT } \\
\hline & & & & & DP & MP & & \\
\hline 1 & Human & AD patient & Female & $73 y$ & + & + & + & + \\
\hline 2 & Japanese macaque & NA & unknown & $>26 y$ & + & + & + & - \\
\hline 3 & Dog & Miniture.dax & Female & $13 y$ & + & - & + & - \\
\hline 4 & Dog & Beagle & Male & $14 \mathrm{y}$ & + & - & + & - \\
\hline 5 & Dog & Mongrel & Male & $14 y$ & + & + & + & - \\
\hline 6 & Dog & unknown & unknown & $14 y$ & + & + & + & - \\
\hline 7 & Dog & unknown & unknown & $18 \mathrm{y}$ & + & + & + & - \\
\hline 8 & Dog & Maltese & unknown & $18 \mathrm{y}$ & + & - & + & - \\
\hline 9 & Dog & Mongrel & Female & $20 \mathrm{y}$ & + & - & + & - \\
\hline 10 & Cat & Monglel & Female & $20 y$ & + & - & + & - \\
\hline 11 & American black bear & NA & Female & $20 \mathrm{y}$ & + & + & + & - \\
\hline 12 & Bactrian camel & NA & Female & $>20 y$ & + & - & - & - \\
\hline 13 & Great spotted woodpecker & NA & Male & $>16 y$ & - & - & + & - \\
\hline 14 & Mouse & APP23Tg & Female & $30 \mathrm{~m}$ & + & + & + & - \\
\hline
\end{tabular}

SP: Senile plaque, DP: Diffuse plaque, MP: Mature plaque, CAA: Cerebral amyloid angiopathy, NFT: Neurofibrillary tangle, y: Years, m: Months, and NA: Not applicable.

in a $10 \%$ neutral-buffered formalin solution and embedded in paraffin by a routine procedure.

Paraffin sections (4 to $8 \mu \mathrm{m}$ thick) were stained with alkaline Congo red or PAM to detect SPs and CAA. In addition, sections from the AD brain were stained with Gallyas silver [4] to detect NFTs. The sections were preferably compared at the same regions.

Immunohistochemistry: Immunostaining with anti-A $\beta 1$ 42 (A $\beta 42$ : $\mathrm{BC} 05, \mathrm{~A} \beta$-Protein Immunohistostain Kit, Wako, Osaka, Japan) and anti-A $\beta$ 1-40 (A $\beta 40$ : BA27, A $\beta$-Protein Immunohistostain Kit, Wako) antibodies was carried out in accordance with the manufacturer's procedure for the $A \beta$ Protein Immunohistostain Kit (Wako). Immunostaining with anti-PHF-tau antibody (PHF-tau: AT8, $10 \mu \mathrm{g} / \mathrm{m} l$, Thermo, Kanagawa, Japan) was carried out in the following methods. Deparaffinized sections were first autoclaved at $120^{\circ} \mathrm{C}$ for $10 \mathrm{~min}$ in $10 \mathrm{mM}$ citrate buffer for antigen retrieval. Tissue sections were then treated with $1 \%$ hydrogen peroxide in methanol for $3 \mathrm{~min}$ to inhibit endogenous peroxidase activity and further incubated in $8 \%$ skimmed milk in tris-buffered saline (TBS) at $37^{\circ} \mathrm{C}$ for $30 \mathrm{~min}$ to block nonspecific reactions. The sections were incubated with a primary antibody at $4^{\circ} \mathrm{C}$ overnight. Following 3 washings in TBS, sections were then incubated with an HRP-labeled polymer-conjugated secondary antibody against mouse $\operatorname{IgG}$ (Dako Japan, Kyoto, Japan) at $37^{\circ} \mathrm{C}$ for $60 \mathrm{~min}$. Finally, the reaction products were visualized with $0.05 \%$ 3-3'-diaminobenzidine and $0.03 \%$ hydrogen peroxide in tris- $\mathrm{HCl}$ buffer. Counterstaining was carried out with Mayer's hematoxylin.

Curcumin staining: Deparaffinized sections were immersed in $80 \%$ ethanol, $0.3 \%$ Triton $\mathrm{X}-100$, and $0.1 \mathrm{M}$ TBS (pH 7.4) containing 3\% bovine serum albumin (BSA) and $0.5 \%$ Tween 20 , for $10 \mathrm{~min}$ each. Curcumin powder (Cayman Chemical Company, Ann Arbor, MI, U.S.A.) was resolved in $0.1 \mathrm{M}$ TBS ( $\mathrm{pH} 7.4$ ) containing 3\% BSA and $0.5 \%$ Tween 20 at $25 \mu \mathrm{M}(0.009 \%$ curcumin solution $)$. Sec- tions were incubated with the curcumin solution at $37^{\circ} \mathrm{C}$ for $60 \mathrm{~min}$. Following 3 washings in TBS, the sections were rinsed once in distilled water (DW), and coverslipped with a non-fluorescent mounting medium. All sections were examined using a confocal laser scanning microscope (LSM510, Carl Zeiss, Oberkochen, Germany) (green: excitation wavelength $488 \mathrm{~nm} /$ emission filter 505 to $550 \mathrm{~nm}$, red: excitation wavelength $488 \mathrm{~nm} /$ emission filter over 650 $\mathrm{nm}$ ) or a fluorescence microscope (DMI3000B, Leica microsystems, Wetzlar, Germany) (green: excitation filter $470 \pm 40 \mathrm{~nm} / \mathrm{emission}$ filter $525 \pm 50 \mathrm{~nm}$, red: excitation filter $546 \pm 12 \mathrm{~nm} /$ emission filter $605 \pm 75 \mathrm{~nm}$ ). Emission wavelength of curcumin in water is about $550 \mathrm{~nm}$ when excited with wavelength $430 \mathrm{~nm}$ [15]. In the present study, we used merged pictures of red and green fluorescences to obtain higher-contrasted pictures (Fig. 1). Furthermore, some sections were stained with curcumin after a 5-min pretreatment with $99 \%$ formic acid (Wako).

Image processing: $\mathrm{A} \beta 40$ - or $\mathrm{A} \beta 42$-positive areas (pixels) were measured in randomly selected regions of the cerebral cortex of each section using the Image J image analysis software (NIH, Bethesda, MD, U.S.A.). The means of the data were analyzed by Student's $t$-test.

\section{RESULTS}

Immunohistochemistry: A $\beta 40$ - or A $\beta 42$-positive SPs were found in the brains of all animals except for a woodpecker (Table 1 and Fig. 2). In the brains of an AD patient, a monkey, a bear, a camel, and a APP Tg-mouse, most SPs were distinct, whereas those of dogs and cats had an indistinct boundary. In the brains of an AD patient, dogs, and a bear, A $\beta 42$-positive SPs were observed more than A $\beta 40$ positive SPs. In the brains of cats and a camel, the majority of SPs were positive for $A \beta 42$ and negative for $A \beta 40$. In a monkey and a APP Tg-mouse, there was no difference between $A \beta 42-$ and $A \beta 40$-positive areas (Fig. 2). 

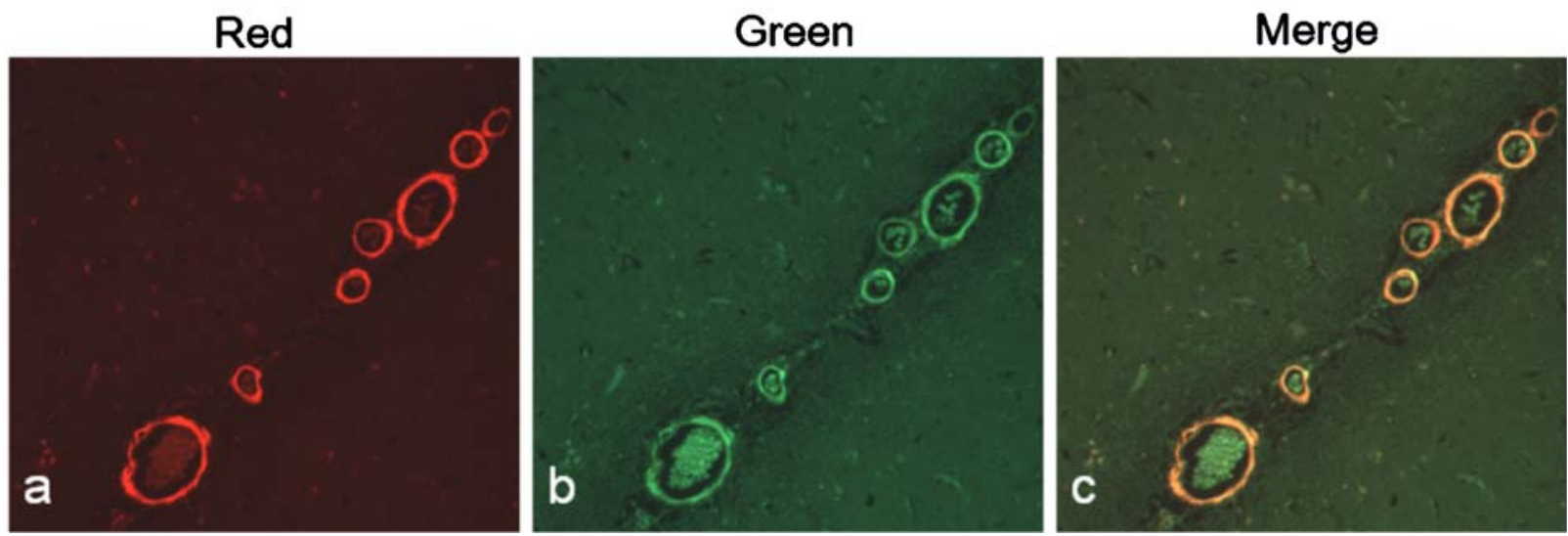

Fig. 1. A curcumin stained section of a Japanese macaque. A $\beta$-positive meningeal vessels are depicted with (a) red fluorescence (excitation filter $546 \pm 12 \mathrm{~nm} /$ emission filter $605 \pm 75 \mathrm{~nm}$ ) or (b) green fluorescence (excitation filter $470 \pm 40 \mathrm{~nm} /$ emission filter $525 \pm 50 \mathrm{~nm}$ ) and the pictures are merged $(c)$.

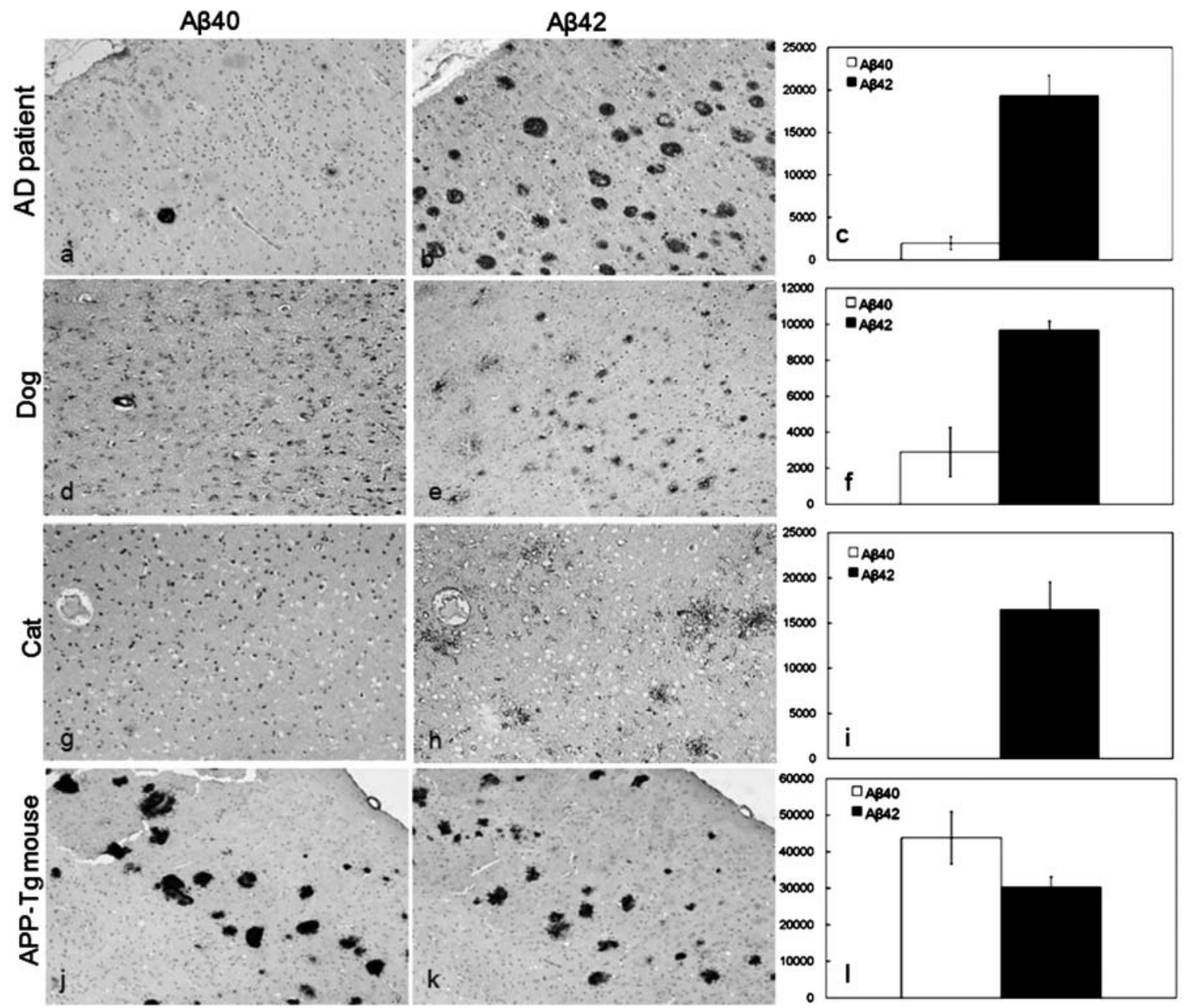

Fig. 2. Immunostain for SPs using antibodies for $A \beta 40(a, d, g, j)$ and $A \beta 42(b, e, h, k)$, and the semi-quantitative data $(c, f, i, l)$

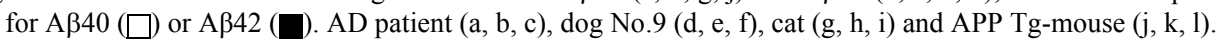




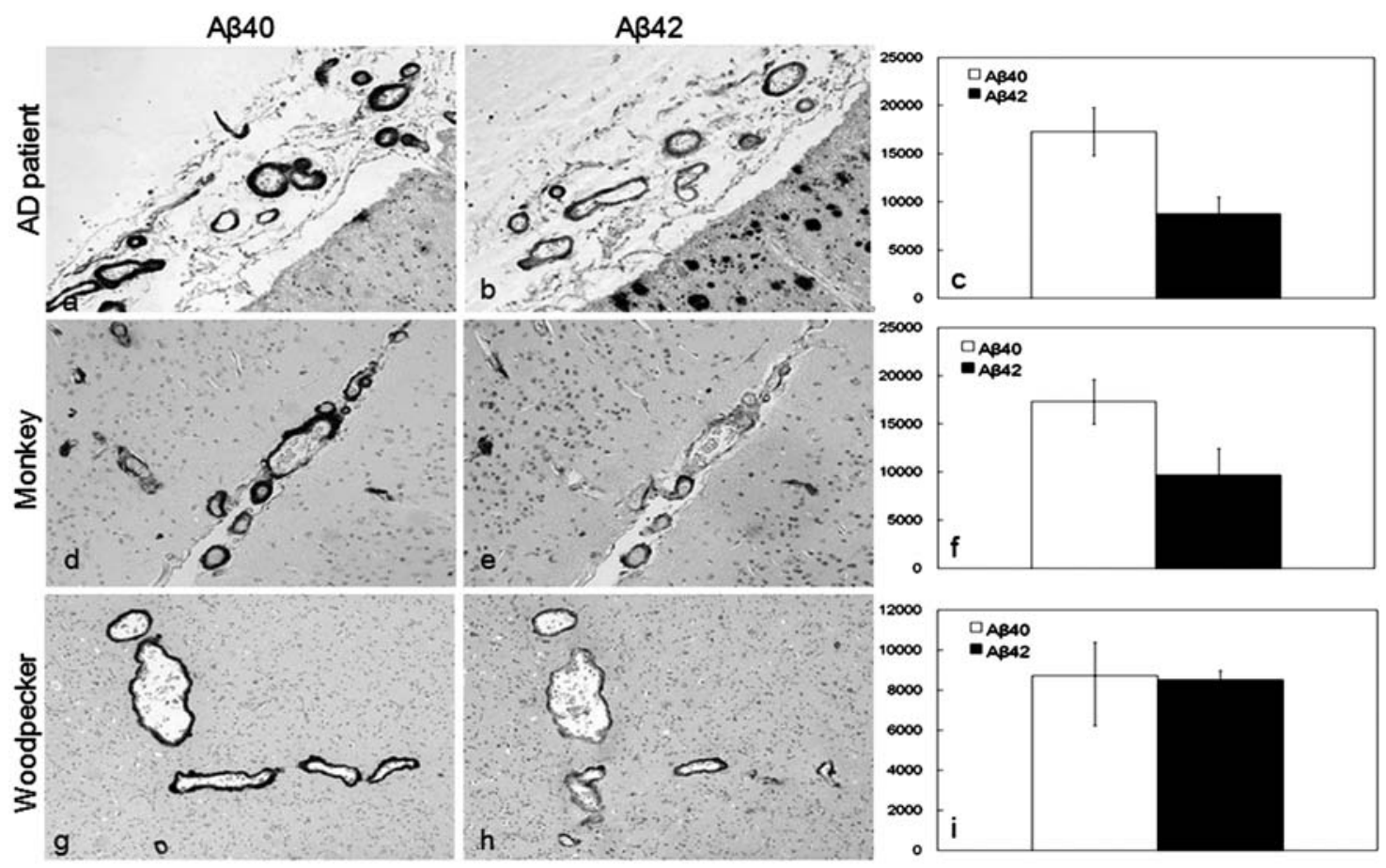

Fig. 3. Immunostain for CAA using antibodies for $A \beta 40(a, d, g)$ and $A \beta 42(b, e, h)$, and the semi-quantitative data (c, f, i) for $\mathrm{A} \beta 40(\square)$ or A $\beta 42(\square)$. AD patient (a, b, c), Japanese macaque (d, e, f) and great spotted woodpecker (g, h, i).
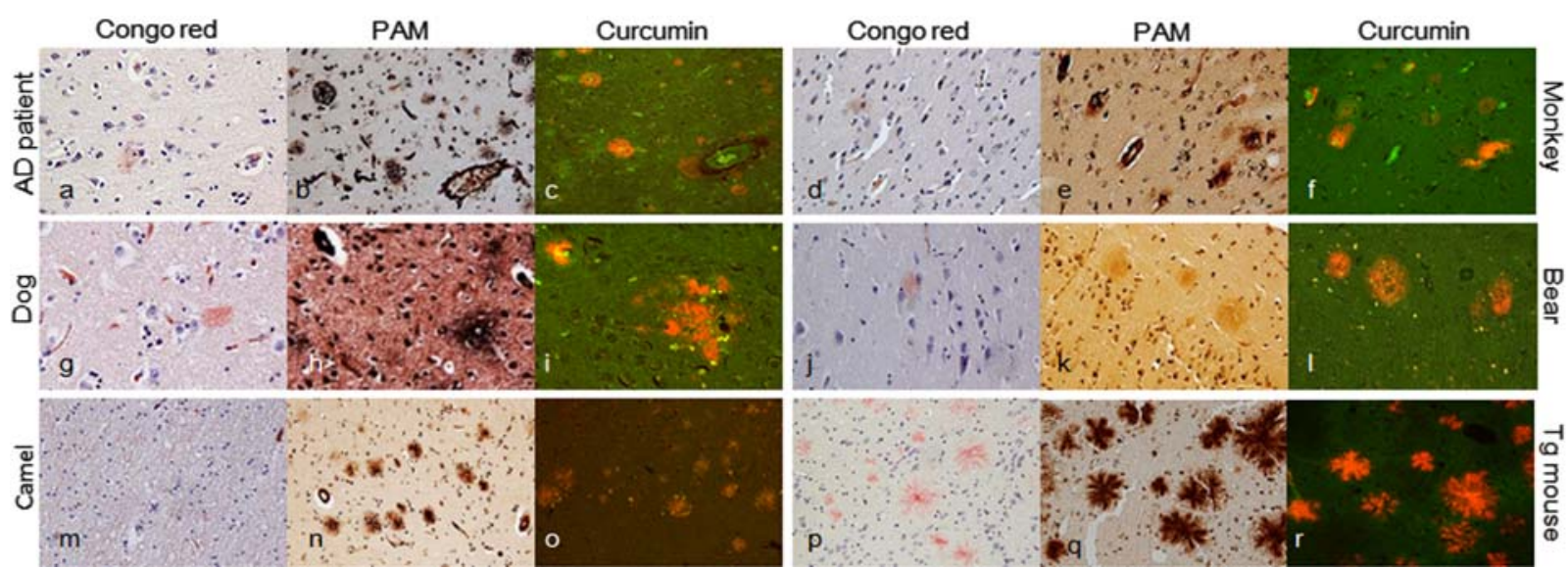

Fig. 4. Comparison of Congo red stain (a, d, g, j, m, p), PAM stain (b, e, h, k, n, q) and curcumin stain (c, f, i, l, o, r) for SPs. AD patient (a, b, c), Japanese macaque (d, e, f), dog No. 5 (g, h, i), American black bear (j, k, l), Bactrian camel (m, n, o) and APP Tg-mouse (p, q, r).

CAA was observed in the meningeal and parenchymal vessels and capillaries of all animal species excluding a camel by both $A \beta 42$ and $A \beta 40$ immunostains (Table 1 and Fig. 3). CAA was labeled more intensely for $A \beta 40$ compared with that for $\mathrm{A} \beta 42$ (Fig. 3).

NFTs were found only in the AD brain by PHF-tau immunostain (Table 1).

Curcumin stain: SPs (Fig. 4): Both congophilic MPs and Congo red-negative DPs were observed in the $\mathrm{AD}$, monkey, bear, and APP Tg-mouse brains. Curcumin stained all these
SPs. DPs were found in all dogs examined, whereas a few MPs were found only in three dogs (Nos. 5, 6, and 7). Such canine MPs were intensely stained with curcumin, but canine DPs were negative. In the camel, only DPs were found and they were positive for curcumin. A $\beta 42$-positive deposits were found in the cat brain, but they were negative for curcumin as well as Congo red and PAM.

CAA (Fig. 5): In all animals except for a camel, CAA was intensely stained with curcumin. In a woodpecker and some dogs, perivascular $A \beta$ deposits were also intensely positive 

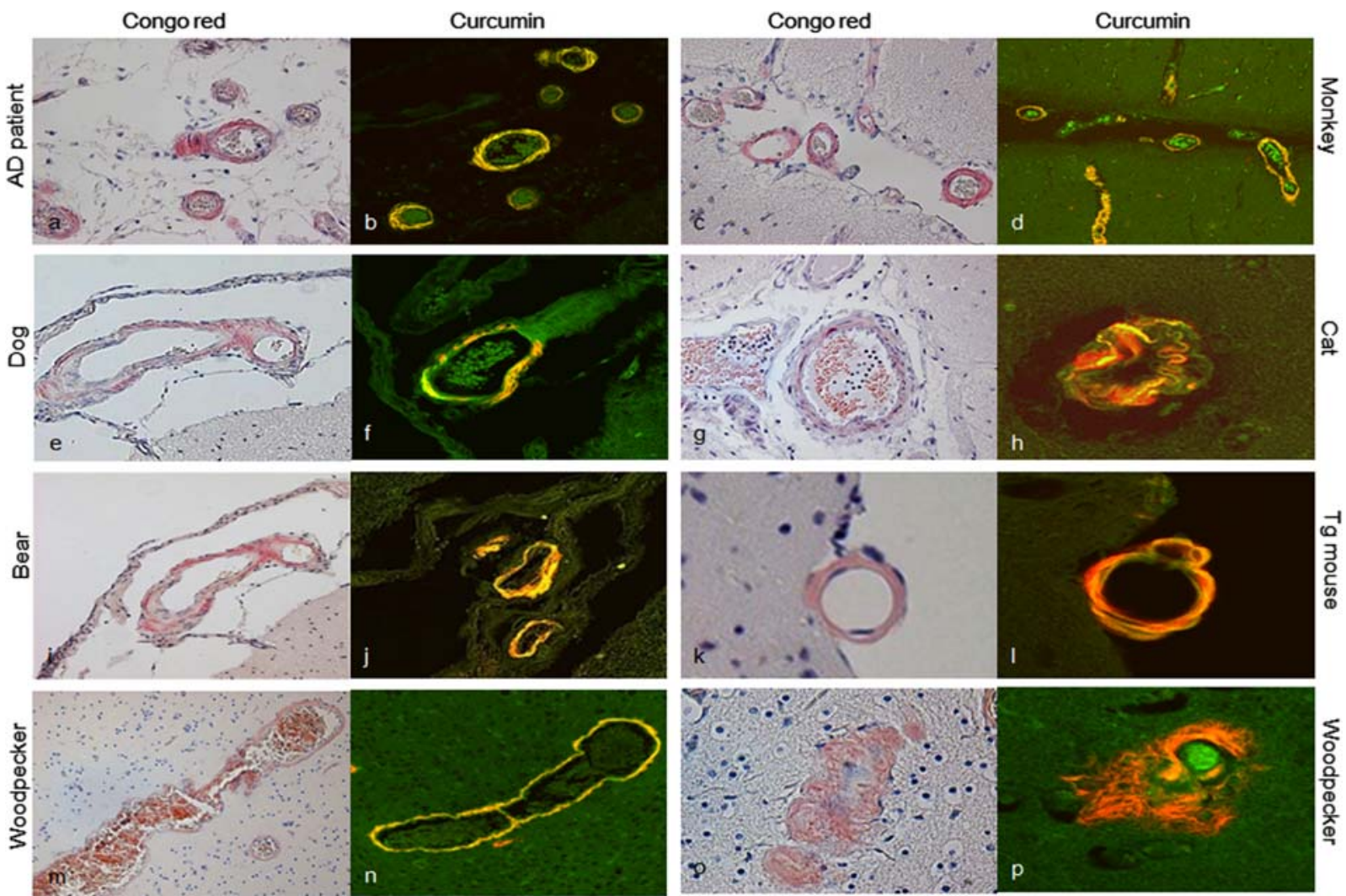

Fig. 5. Comparison of Congo red stain (a, c, e, g, i, k, m, o) and curcumin stain (b, d, f, h, j, l, n, p) for CAA. AD patient (a,b), Japanese macaque (c, d), dog No. 5 (e, f), cat (g, h), American black bear(i, j), APP Tg-mouse (k, l), great spotted woodpecker(m, n), and perivascular $\mathrm{A} \beta$-positive deposits in the great spotted woodpecker $(o, p)$.

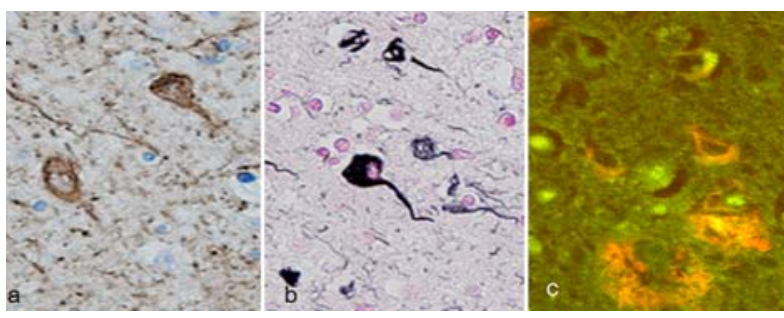

Fig. 6. NFTs in the cerebral cortex of an AD patient. Immunostain for PHF-tau (a), Gallyas silver stain (b) and curcumin stain (c).

for Congo red and curcumin (Fig. 5-o, p).

NFTs (Fig. 6): NFTs found in the AD brain were positive for Gallyas silver and curcumin. Gallyas silver stain was more sensitive than curcumin stain.

Formic acid pretreatment (Fig. 7): By formic acid pretreatment, curcumin-positive SPs and CAA in all animal species became negative.

\section{DISCUSSION}

DPs are thought to be the initial stage of plaque forma- tion, and they are negative for Congo red [29]. In contrast, MPs are plaques of the more progressive stages, and they are positive for Congo red [28]. Both DPs and MPs can be detected by PAM stain and $A \beta$ immunostain $[25,29]$. The present study revealed that DPs were found in all animals other than the woodpecker, and MPs were found in the AD patient, monkey, dog, bear, and APP Tg-mouse (Table 1), indicating the difference of $A \beta$ aggregation status among stages and animal species.

The shape of SPs in the APP Tg-mouse was flower-like and different from that in other animals. Artificially overexpressed APP may induce such abnormal $A \beta$ aggregates in the mouse. In addition, SPs in the APP Tg-mouse were more strongly stained with curcumin than those in $A D$ patients and other animal species. These results indicate that highly aggregated $A \beta$ is apt to bind to curcumin. On the other hand, curcumin did not stain canine and feline DPs. Generally, most canine and all feline SPs are DPs [26], and they had indistinct boundaries. Feline SPs are formed in very old animals, suggesting that such feline $A \beta$ aggregates occur at the very early stage of SP formation [18]. Thus, $A \beta$ in canine and feline DPs may be less aggregated than that in $\mathrm{AD}$ patient and monkey. These findings also indicate that curcumin may bind to $A \beta$ aggregates at later stages. Further- 

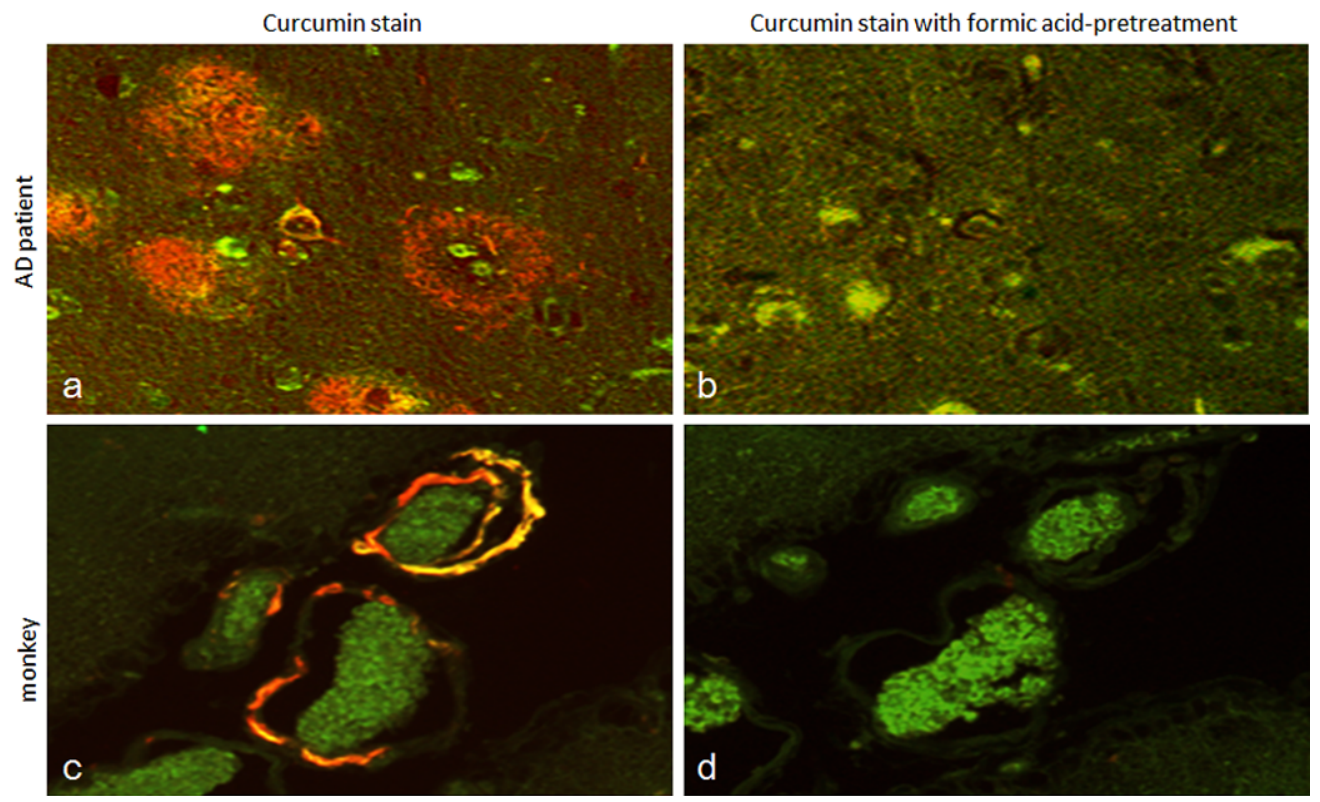

Fig. 7. Curcumin stain without formic acid pretreatment (a, c) and Curcumin stain with formic acid pretreatment $(b, d)$. SPs of an AD patient $(a, b)$ and CAA of a Japanese macaque (c, d).

more, DPs in the AD patient, monkey, bear, camel and APP Tg-mouse were stained with curcumin. It is thought that curcumin binds to SPs more sensitively than Congo red, since Congo red-negative DPs were positive for curcumin.

By formic acid pretreatment, the binding of curcumin to SPs, CAA, and NFTs was lost. For the A $\beta$ immunostain, formic acid pretreatment is used to restore and reinforce $A \beta$ immunoreactivity [12]. Formic acid more likely solubilizes $\mathrm{A} \beta$-derived amyloid fibrils and therefore disrupts the polymer fibrillar configuration while exposing the $A \beta$ epitopes. The disrupted structures enhance the immunoreactivity of the antibody to $A \beta$. However, $A \beta$ could bind to neither Congo red nor curcumin when its protein structure was lost. Since the chemical structure of curcumin is partly similar to that of Congo red [30], curcumin may bind to the $A \beta$ aggregates by the recognition of their structure by a similar manner to that of Congo red.

Generally, it is thought that SPs in human mainly consist of $A \beta 42$, and CAA consists of $A \beta 40$. It has also been shown that DPs of AD patients and dogs mainly consist of $\mathrm{A} \beta 42$, and their MPs mainly consist of $A \beta 40$ [16]. The present study indicated that most SPs consist of $\mathrm{A} \beta 42$ in $\mathrm{AD}$, dog, bear, camel, and cat brains, whereas most SPs consist of both $\mathrm{A} \beta 42$ and $\mathrm{A} \beta 40$ in monkey and APP Tg-mouse brains. Regarding CAA, it mainly consists of $A \beta 40$ and $A \beta 42$ in the $\mathrm{AD}$, monkey, cat, APP Tg-mouse, and woodpecker brains, whereas CAA consists of A $\beta 40$ in the dog and bear. Curcumin stained both SPs and CAA, which were positive for $A \beta 40$ and/or $A \beta 42$ in the present study. These results suggest that the binding of curcumin to $A \beta$ does not depend on the C-terminal structure of $\mathrm{A} \beta$.

In the present study, NFTs in the AD brain were stained with curcumin as described in a previous report [14]. However, the Gallyas silver stains labeled NFTs more sensitively than curcumin stain. This result indicates that curcumin binds to abnormal tau protein, but the binding activity is weaker than that to $A \beta$, and reveals the limited utility of curcumin stain for the detection of NFTs.

In conclusion, curcumin can bind specifically to abnormal tau proteins as well as to highly aggregated $A \beta$. Such curcumin binding is more sensitively than Congo red. Furthermore, curcumin stain is more simple and less nonspecific than Congo red stain. The present results clearly indicate the utility of curcumin as a specific marker for $A \beta$ detection in various animals.

ACKNOWLEDGMENTS. This work was supported by the URAKAMI FOUNDATION. The authors would like to express their sincere gratitude to the foundation, and also to Dr. Takane Matsui, a professor of Obihiro University of Agriculture and Veterinary Medicine for his offer of valuable materials.

\section{REFERENCES}

1. Aggarwal, B. B., Kumar, A. and Bharti, A. C. 2003. Anticancer potential of curcumin: preclinical and clinical studies. Anticancer Res. 23: 363-398.

2. Begum, A. N., Jones, M. R., Lim, G. P., Morihara, T., Kim, P., Heath, D. D., Rock, C. L., Pruitt, M. A., Yang, F., Hudspeth, B., Hu, S., Faull, K. F., Teter, B., Cole, G. M. and Frautschy, S. A. 2008. Curcumin structure-function, bioavailability, and efficacy in models of neuroinflammation and Alzheimer's disease. J. Pharmacol. Exp. Ther. 326: 196-208.

3. Borrás, D., Ferrer, I. and Pumarola, M. 1999. Age-related 
changes in the brain of the dog. Vet. Pathol. 36: 202-211.

4. Braak, H., Braak, E., Ohm, T. and Bohl, J. 1988. Silver impregnation of Alzheimer's neurofibrillary changes counterstained for basophilic material and lipofuscin pigment. Stain Technol. 63: 197-200.

5. Braak, H., Braak, E. and Strothjohann, M. 1994. Abnormally phosphorylated tau protein related to the formation of neurofibrillary tangles and neuropil threads in the cerebral cortex of sheep and goat. Neurosci. Lett. 171: 1-4.

6. Cork, L. C., Powers, R. E., Selkoe, D. J., Davies, P., Geyer, J. J. and Price, D. L. 1988. Neurofibrillary tangles and senile plaques in aged bears. J. Neuropathol. Exp. Neurol. 47: 629641.

7. Elfenbein, H. A., Rosen, R. F., Stephens, S. L., Switzer, R. C., Smith, Y., Pare, J., Mehta, P. D., Warzok, R. and Walker, L. C. 2007. Cerebral beta-amyloid angiopathy in aged squirrel monkeys. Histol. Histopathol. 22: 155-167.

8. Frautschy, S. A., Hu, W., Kim, P., Miller, S. A., Chu, T., Harris-White, M. E. and Cole, G. M. 2001. Phenolic anti-inflammatory antioxidant reversal of Abeta-induced cognitive deficits and neuropathology. Neurobiol. Aging 22: 993-1005.

9. Fukuoka, A., Nakayama, H. and Doi, K. 2004. Immunohistochemical detection of beta-amyloid and beta-amyloid precursor protein in the canine brain and non-neuronal epithelial tissues. Amyloid 11: 173-178.

10. Garcia-Alloza, M., Borrelli, L. A., Rozkalne, A., Hyman, B. T. and Bacskai, B. J. 2007. Curcumin labels amyloid pathology in vivo, disrupts existing plaques, and partially restores distorted neurites in an Alzheimer mouse model. J. Neurochem. 102: 1095-1104.

11. Hamaguchi, T., Ono, K., Murase, A. and Yamada, M. 2009. Phenolic compounds prevent Alzheimer's pathology through different effects on the amyloid-beta aggregation pathway. Am. J. Pathol. 175: 2557-2565.

12. Kitamoto, T., Ogomori, K., Tateishi, J. and Prusiner, S. B. 1987. Formic acid pretreatment enhances immunostaining of cerebral and systemic amyloids. Lab. Invest. 57: 230-236.

13. Lim, G. P., Chu, T., Yang, F., Beech, W., Frautschy, S. A. and Cole, G. M. 2001. The curry spice curcumin reduces oxidative damage and amyloid pathology in an Alzheimer transgenic mouse. J. Neurosci. 21: 8370-8377.

14. Mohorko, N., Repovs, G., Popović, M., Kovacs, G. G. and Bresjanac, M. 2010. Curcumin labeling of neuronal fibrillar tau inclusions in human brain samples. J. Neuropathol. Exp. Neurol. 69: 405-414.

15. Mukerjee, A., Sørensen, T. J., Ranjan, A. P., Raut, S., Gryczynski, I., Vishwanatha, J. K. and Gryczynski, Z. 2010. Spectroscopic properties of curcumin: orientation of transition moments. J. Phys. Chem. B 114: 12679-12684.

16. Nakamura, S., Tamaoka, A., Sawamura, N., Kiatipattanasakul, W., Nakayama, H., Shoji, S., Yoshikawa, Y. and Doi, K. 1997. Deposition of amyloid beta protein $(A \beta)$ subtypes $[A \beta 40$ and A $\beta 42(43)]$ in canine senile plaques and cerebral amyloid angiopathy. Acta Neuropathol. 94: 323-328.

17. Nakamura, S., Nakayama, H., Goto, N., Ono, F., Sakakibara, I. and Yoshikawa, Y. 1998. Histopathological studies of senile plaques and cerebral amyloidosis in cynomolgus monkeys. $J$. Med. Primatol. 27: 244-252.

18. Nakamura, S., Nakayama, H., Kiatipattanasakul, W., Uetsuka, K., Uchida, K. and Goto, N. 1996. Senile plaques in very aged cats. Acta Neuropathol. 91: 437-439.

19. Nakamura, S., Nakayama, H., Uetsuka, K., Sasaki, N., Uchida, K. and Goto, N. 1995. Senile plaques in an aged two-humped (Bactrian) camel (Camelus bactrianus). Acta Neuropathol. 90: 415-418.

20. Nakayama, H., Katayama, K., Ikawa, A., Miyawaki, K., Shinozuka, J., Uetsuka, K., Nakamura, S., Kimura, N., Yoshikawa, Y. and Doi, K. 1999. Cerebral amyloid angiopathy in an aged great spotted woodpecker (Picoides major). Neurobiol. Aging 20: 53-56.

21. Podlisny, M. B., Tolan, D. R. and Selkoe, D. J. 1991. Homology of the amyloid beta protein precursor in monkey and human supports a primate model for beta amyloidosis in Alzheimer's disease. Am. J. Pathol. 138: 1423-1435.

22. Roertgen, K. E., Parisi, J. E., Clark, H. B., Barnes, D. L., O'Brien, T. D. and Johnson, K. H. 1996. A beta-associated cerebral angiopathy and senile plaques with neurofibrillary tangles and cerebral hemorrhage in an aged wolverine (Gulo gulo). Neurobiol. Aging 17: 243-247.

23. Rosen, R.F., Farberg, A.S., Gearing, M., Dooyema, J., Long, P. M., Anderson, D. C., Davis-Turak, J., Coppola, G., Geschwind, D. H., Paré, J. F., Duong, T. Q., Hopkins, W. D., Preuss, T. M. and Walker, L. C. 2008. Tauopathy with paired helical filaments in an aged chimpanzee. J. Comp. Neurol. 509: 259-270.

24. Selkoe, D. J., Bell, D. S., Podlisny, M. B., Price, D. L. and Cork, L. C. 1987. Conservation of brain amyloid proteins in aged mammals and humans with Alzheimer's disease. Science 235: 873-877.

25. Tagliavini, F., Giaccone, G., Frangione, B. and Bugiani, O. 1988. Preamyloid deposits in the cerebral cortex of patients with Alzheimer's disease and nondemented individuals. $\mathrm{Neu}$ rosci. Lett. 93: 191-196.

26. Uchida, K., Nakayama, H. and Goto, N. 1991. Pathological studies on cerebral amyloid angiopathy, senile plaques and amyloid deposition in visceral organs in aged dogs. J. Vet. Med. Sci. 53: 1037-1042.

27. Uchida, K., Yoshino, T., Yamaguchi, R., Tateyama, S., Kimoto, Y., Nakayama, H. and Goto, N. 1995. Senile plaques and other senile changes in the brain of an aged American black bear. Vet. Pathol. 32: 412-414.

28. Wisniewski, H. M. and Terry, R. D. 1973. Reexamination of the pathogenesis of the senile plaques. Prog. Neuropathol. 2: $1-26$.

29. Yamaguchi, H., Hirai, S., Morimatsu, M., Shoji, M. and Harigaya, Y. 1988. Diffuse type of senile plaques in the brains of Alzheimer-type dementia. Acta Neuropathol. 77: 113-119.

30. Yang, F., Lim, G. P., Begum, A. N., Ubeda, O. J., Simmons, M. R., Ambegaokar, S. S., Chen, P. P., Kayed, R., Glabe, C. G., Frautschy, S. A. and Cole, G. M. 2005. Curcumin inhibits formation of amyloid beta oligomers and fibrils, binds plaques, and reduces amyloid in vivo. J. Biol. Chem. 280: 5892-5901. 